\title{
ERYTHROCYTE PRESERVATION. I. THE RELATION OF THE STORAGE LESION TO IN VIVO ERYTHROCYTE SENESCENCE ${ }^{1}$
}

\author{
By BEVERLY WESCOTT GABRIO AND CLEMENT A. FINCH WITH THE TECHNICAL \\ ASSISTANCE OF WILBUR LINDE AND ALICE RUPEN
}

\author{
(From the Department of Medicine, University of Washington School of Medicine, and the \\ King County Central Blood Bank, Seattle, Wash.)
}

(Submitted for publication June 8, 1953; accepted September 30, 1953)

Erythrocytes stored in an acid-citrate-dextrose preservative (ACD) at 4 to $7^{\circ} \mathrm{C}$. undergo morphological and biochemical alterations. The cell becomes more sphere-shaped with an associated increase in osmotic and mechanical fragilities, the glycolytic rate and organic phosphate compounds are decreased, inorganic phosphate is increased, and the differential between cell potassium and sodium is decreased (1). These altered cells, when transfused to a recipient, are destroyed in an amount dependent upon the duration of storage of the blood. Thus, storage for three weeks in ACD results in a viability ${ }^{2}$ of about 85 per cent and for four weeks in a viability of about 60 per cent $(2,3)$. Since the normal human erythrocyte population is destroyed in vivo at a rate of 0.8 to 1.0 per cent per day, the survival of erythrocytes after three to four weeks of storage is consistent with the expected in vivo loss from aging. The present study was undertaken to determine whether the changes of storage were related to a normal or accelerated aging process, or whether they represented cell damage due to in vitro storage conditions.

\section{MATERIALS AND METHODS}

\section{Preparation of an erythrocyte population of uniform age}

Two dogs were bled daily over a period of 16 days to a total of about $4,800 \mathrm{ml}$. of blood per dog. Calculations based on serial blood volume determinations by the T1824 dye technique (4) and blood withdrawn indicated that over 90 per cent of the original erythrocytes had

1 This investigation was supported in part by research grants from the United States Atomic Energy Commission (Contract AT (45-1)-343) and the United States Public Health Service (Contract H-1179 (C1).

2 The term, viability, will be used throughout this series of papers to describe the maintenance of erythrocytes in circulation after transfusion into a suitable recipient. Thus, loss of viability refers to the excessive loss of erythrocytes from the circulation after transfusion but does not necessarily define the metabolic state of the cell. been removed. Saccharated iron oxide ${ }^{8}(2,400 \mathrm{mg}$. of iron) was injected during this period to allow rapid blood regeneration. The red cell mass returned to normal by the 14th day after the last phlebotomy; thus a population of new red cells of uniform age ( \pm 7 days) had been formed.

\section{Chemical methods}

For the storage of blood at $4^{\circ} \mathrm{C}$, acid-citrate-dextrose (ACD) preservative was used routinely in the proportion of one volume to four volumes of blood. The final concentration of preservative components was approximately 0.264 per cent sodium citrate, 0.096 per cent citric acid, and 0.294 per cent glucose.

Osmotic fragility was measured by the method of Shen, Ham, and Fleming (5), and mechanical fragility determinations were performed according to a slight modification of the technique of Shen, Castle, and Fleming (6).

Phosphate partitions were performed on cold trichloracetic acid filtrates of 0.9 per cent $\mathrm{NaCl}$ suspensions of erythrocytes from which most of the leucocytes had been removed. No essential difference was found between the red cell phosphate partition of blood collected in 95 per cent $\mathrm{O}_{2}-5$ per cent $\mathrm{CO}_{2}$ and of blood carefully collected and handled in an air atmosphere. After blood collection, all manipulations prior to analyses were performed at $4^{\circ} \mathrm{C}$. The inorganic, total, 7 minute-hydrolyzable, and 100 minute-hydrolyzable phosphorus values were determined by the Gomori (7) modification of the Fiske and Subbarow method (8). The hydrolyses were carried out for 7 and 100 minutes in $1 \mathrm{~N} \mathrm{H}_{2} \mathrm{SO}_{4}$ at $100^{\circ} \mathrm{C}$. By means of these analyses the following acid soluble fractions of the red cell have been assayed $(9,10): 1$. Inorganic phosphate; 2. total phosphate; 3. labile phosphorus released from adenosine polyphosphates, largely ATP, after 7 minute hydrolysis (easily hydrolyzable ); 4. phosphorus derived primarily from adenylic acid and hexose phosphates after 100 minute hydrolysis (difficultly hydrolyzable ) ; 5 . phosphorus represented largely by 2,3-diphosphoglycerate and calculated by subtracting fractions 1,3 , and 4 from the total phosphorus (non-hydrolyzable).

Glucose utilization was measured by $\mathrm{CO}_{2}$ evolution on washed cells suspended in Krebs-Ringer bicarbonate solu-

8 We are indebted to Smith, Kline, and French Laboratories for the feojectin (saccharated iron oxide) used in these experiments. 
tion at $37^{\circ} \mathrm{C}$. in a 95 per cent $\mathrm{N}_{2}-5$ per cent $\mathrm{CO}_{2}$ atmosphere in the conventional Warburg apparatus.

\section{Radioactive techniques of measuring erythrocyte viability}

Radioactive tagging of animal erythrocytes was accomplished by the intravenous injection of tracer amounts of $\mathrm{Fe}^{\mathrm{ss}}$ or $\mathrm{Fe}^{\infty}$. Such iron is rapidly incorporated into the maturing red cell within the bone marrow and remains within the cell through its life span (11). In this manner a population of erythrocytes of known and uniform age may be tagged. The determination of the survival of labeled cells is limited to a period of 24 hours after transfusion to a recipient animal, since iron from destroyed erythrocytes is reutilized and appears in new circulating erythrocytes after this time interval. In the studies reported here, two populations of cells were injected: (a) Stored blood tagged with one radioisotope of iron; and (b) fresh blood containing a second radioisotope of iron. The ratio of radioactivity of the two isotopes in the cell mixture before and at intervals after transfusion indicated the survival of stored cells as compared with that of fresh cells. Processing of blood samples and the determination of radioactivity have been described (12). $\mathrm{Fe}^{\mathrm{so}}$ was counted with a helium-filled Geiger tube, and an argon-filled tube and beryllium filter were used for $\mathrm{Fe}^{\mathrm{ss}}$.

\section{RESULTS}

\section{Studies on Erythrocyte Senescence In Vivo}

A young population of erythrocytes was created by repeated bleedings in two dogs as previously described. Measurements on this aging cell population were made at intervals of 10 days for a period of 150 days.

Osmotic and mechanical fragility analyses failed to show significant changes over this period of time, and the aging cells did not vary appreciably. in their ability to utilize glucose. The inorganic phosphate content ( $1 \mathrm{mg}$. P per $100 \mathrm{ml} . \mathrm{RBC}$ ) and the organic phosphate content $(53 \mathrm{mg}$. $\mathrm{P}$ per 100 $\mathrm{ml}$. $\mathrm{RBC}$ ) remained constant during the in vivo aging of the erythrocyte mass, while the easily hydrolyzable phosphorus fraction showed only random fluctuations (6.7 to $9.1 \mathrm{mg}$. per $100 \mathrm{ml}$. $\mathrm{RBC}$ in dog I and 5.8 to $8.5 \mathrm{mg}$. in dog II). Thus, the progressive changes characteristic of in vitro storage were not present in the erythrocyte aging in vivo.

\section{Comparison of the Storage Lesion in Rabbit and Human Erythrocytes}

It has been shown that the life-span of the rabbit erythrocyte is approximately one-half that of man (13). Thus, if storage alterations are related to the aging process, it would be anticipated that there would be differences in the rate at which the storage lesion developed as well as in the subsequent post-transfusion survival of the erythrocytes of these two species. The following results do not indicate such a difference.

\section{A. Biochemical changes}

The average changes in the phosphate partition observed in rabbit and human erythrocytes stored for approximately three weeks under similar conditions are reproduced in Table I. Although in-

TABLE I

Changes in phosphate partition of rabbit and human erythrocytes during storage in $A C D$ at $4^{\circ} \mathrm{C}$.

\begin{tabular}{lcrrrrr}
\hline \hline & & \multicolumn{5}{c}{ mg. P/100 ml. erythrocytes } \\
\cline { 3 - 7 } & $\begin{array}{c}\text { Days } \\
\text { storage }\end{array}$ & Inorganic & $\mathrm{EH}^{*}$ & $\mathrm{DH}^{*}$ & Non-H* & Total \\
\hline Rabbit & 0 & 7.35 & 10.44 & 6.45 & 64.29 & 88.53 \\
& 23 & 40.18 & 6.01 & 3.90 & 17.55 & 67.64 \\
& & & & & & \\
Human & 0 & 5.88 & 8.29 & 4.23 & 40.15 & 58.55 \\
& 20 & 27.02 & 5.08 & 2.03 & 14.74 & 48.87
\end{tabular}

* Fraction:

$\mathrm{EH}=$ easily hydrolyzable-

$\mathrm{DH}=$ difficultly hydrolyzable-

Non- $\mathrm{H}=$ non-hydrolyzable-
Predominant constituent: adenosine polyphosphates

hexose phosphates + adenylic acid

2,3-diphosphoglycerate dividual studies have shown as much as a twofold variation in the relative values for the inorganic and easily hydrolyzable phosphate compounds, the data for the two species fall indiscriminately within this range. The total and non-hydrolyzable phosphate components show a similar relative decline in both types of cells. Although the rabbit erythrocyte contains a greater amount of phosphate, the relative changes in comparison with the human cell are the same. Changes in osmotic fragility were also similar. Mechanical fragility of the human erythrocyte increased from 12 to 21 per cent after three weeks of storage, and the rabbit red cell fragility increased similarly from 11.9 to 19.6 per cent.

\section{B. Post-transfusion survival}

Previous investigations of human erythrocyte viability after storage (2) are compared in Figure 1 
with similar studies in rabbits employing identical techniques. In both studies, radioiron had been administered over a prolonged period of time so that it was assumed that a mixed population of erythrocytes was tagged. The 24-hour post-transfusion survival of such labeled erythrocytes of both species was similar during a period of four weeks of storage.

III. Post-transfusion Survival of Stored Erythrocytes Related to Cell Age

\section{A. Comparison of two cell populations of different age}

A donor dog was given $\mathrm{Fe}^{55} \mathrm{Cl}_{3}$ intravenously, and 74 days later was injected with $\mathrm{Fe}^{59} \mathrm{Cl}_{3}$. Six days after the second injection, blood was withdrawn and stored for 22 days. Thus the stored blood contained a population of erythrocytes tagged approximately 74 to 80 days previously

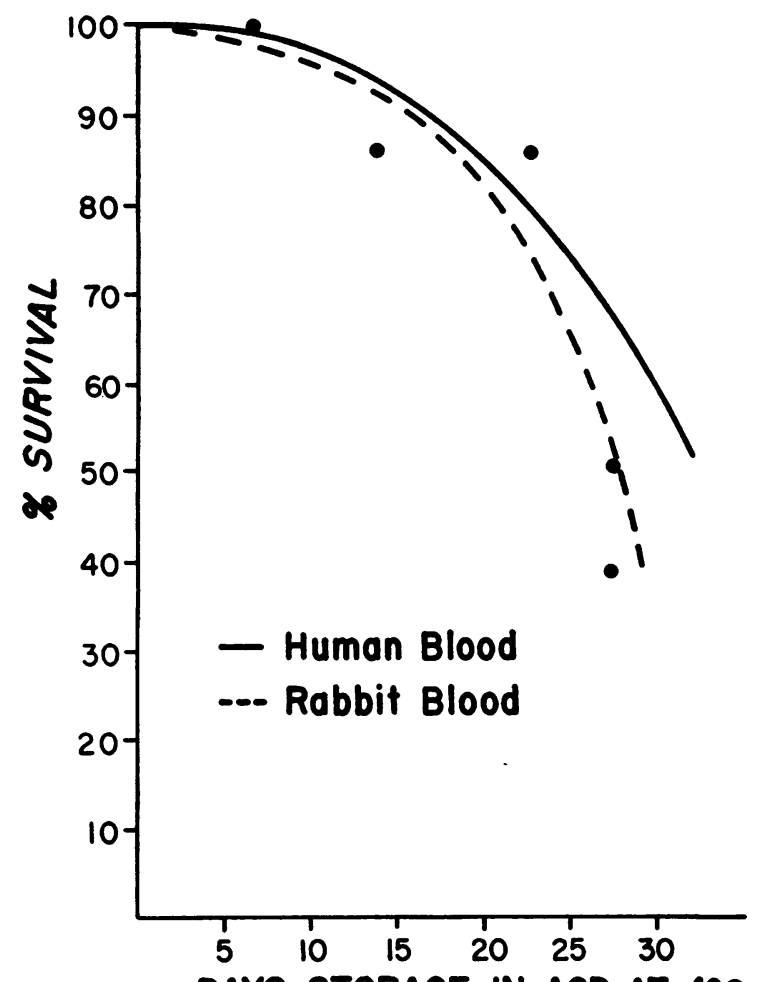

DAYS STORAGE IN ACD AT $4^{\circ} \mathrm{C}$

Fig. 1. The Per Cent Survival of Rabbit Erythrocytes 24 Hours Following Transfusion Is Compared with Previous Studies in Man (2)

Each point represents the viability of a single transfusion of stored rabbit erythrocytes.
TABLE II

Post-transfusion survival ratio of young and old erythrocytes stored at $4^{\circ} \mathrm{C}$. for three weeks

\begin{tabular}{ccc}
\hline & \multicolumn{3}{c}{ Survival ratio $\frac{\mathrm{Fe}^{\mathrm{w}} \text { (young) }}{\mathrm{Fe}_{\text {Time after }}^{\text {Told) }}}$} \\
\cline { 2 - 3 } transfusion & Dog I & Dog II \\
\hline 0 & 1.43 & 1.43 \\
$5 \mathrm{~min}$. & 0.91 & 1.02 \\
$24 \mathrm{hr}$. & 0.43 & 0.61 \\
$48 \mathrm{hr}$. & 0.49 & 0.54 \\
\hline
\end{tabular}

*Young $=$ approximately 6 days. Old $=$ approximately 80 days.

$\left(\mathrm{Fe}^{\mathrm{s5}}\right)$ and a second population only 1 to 6 days old $\left(\mathrm{Fe}^{58}\right)$. This blood was transfused after storage to two recipient dogs, and the ratio of radioactivity $\frac{\mathrm{Fe}^{\mathrm{sg}} \text { (young cells) }}{\mathrm{Fe}^{55} \text { (old cells) }}$ was determined (Table II). The progressive decrease in the ratio over 24 hours indicated that more of the younger cells than old had disappeared from circulation.

\section{$B$. Serial measurements of viability after storage in a single-age population of erythrocytes through their life span.}

A population of red cells was labeled in two donor dogs on day 0 by the injection of $\mathrm{Fe}^{\mathrm{ss}}$ $\mathrm{Cl}_{3}$. At intervals over the following 150 days, blood was withdrawn and stored for 20 and 30 days. Survival of the stored cells was measured by mixing these cells with fresh $\mathrm{Fe}^{59}$ labeled cells and determining the ratio of activity of the two isotopes before and after transfusion ( 5 mins., 6 hrs., 12 hrs., and 24 hrs.) in compatible recipient dogs. The per cent survival of stored blood was calculated from the isotope ratio, assuming that all of the fresh cells survived. In Figure 2 is shown this viability of the tagged cells after a 20-day storage period in relation to their age. There was poor survival during the initial 30 days of their life span, optimal survival at 90 to 100 days and poorer survival thereafter. A similar type of curve was obtained after storage of the same cells for 30 days.

\section{DISCUSSION}

While it has been demonstrated that the erythrocyte of dog and man has a fairly uniform life span of 120 days (11), the factors limiting its in vivo 


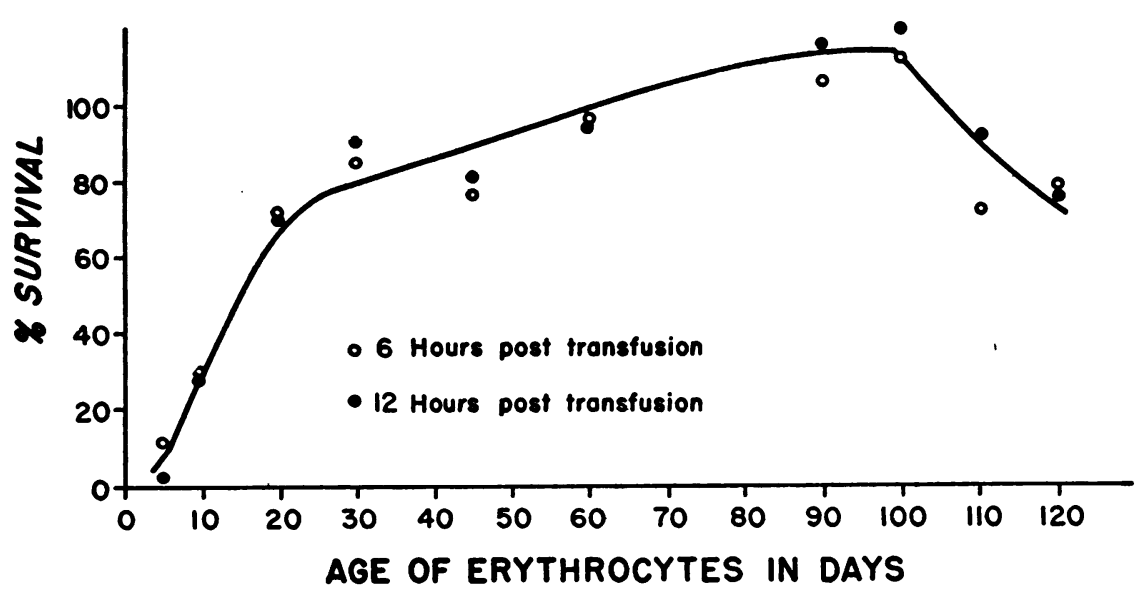

Fig. 2. The Relation of Erythrocyte Age to Post-transfusion Survival after STORAGE

A tagged population of dog erythrocytes was subjected to a 20 -day storage period at intervals throughout its life span. The optimum survival of cells of approximately 90 days of age is apparent.

survival are largely unknown. Although increased mechanical fragility has been demonstrated by a more sensitive technique in the senescent cell (14), its significance is not apparent. In studies on a uniformly aged population of dog erythrocytes, no distinguishing characteristics were found as the cells became old. This is in contrast to the measured changes in erythrocyte fragility, phosphate partition and glucose utilization occurring during storage and would indicate that storage changes are quite different from the aging process of the erythrocyte.

It was also of interest to compare the effect of storage on erythrocytes of another animal species. Rabbit erythrocytes, which have approximately one-half the in vivo life span of human red cells (13), showed a similar rate of biochemical changes and loss of viability. This would indicate that the storage lesion may be studied equally well in other species than man and does not correlate with the in vivo erythrocyte life span.

More definitive information was obtained from a study of the effect of storage on tagged populations of erythrocytes of known age. A greater loss of viability was found in young erythrocytes after storage. More specifically there appeared to be an optimal period between the 90th and 100th days in the life span with poorer survival before and after this interval (Figure 2). The apparent poor survival of older cells could as well reflect the susceptibility of the young erythrocytes which may be present in the mixture, since during this senescent period radioiron is being liberated from destroyed erythrocytes and is appearing in new erythrocytes.

Storage damage to the erythrocyte is clearly separate from the aging process. It seems appropriate to refer to these changes as the storage lesion, a composite of physico-chemical alterations induced by the conditions of storage which may progress to the loss of cell viability.

\section{SUMMARY}

During in vitro storage characteristic changes occur in the fragility, glucose utilization, and in the phosphorylated compounds associated with carbohydrate metabolism of the red cell. These alterations were not found during aging of the erythrocyte in vivo. In different species, storage damage was found to be similar and unrelated to the life span of the erythrocyte. The young erythrocyte was shown to be more susceptible to storage damage than the older cell. It is concluded that the changes of in vitro storage, referred to collectively as the storage lesion, bear no relationship to in vivo senescence of the erythrocyte.

\section{REFERENCES}

1. Rapoport, S., Dimensional, osmotic, and chemical changes of erythrocytes in stored blood. I. Blood preserved in sodium citrate, neutral, and acid ci- 
trate-glucose (ACD) mixtures. J. Clin. Invest., 1947, 26, 591.

2. Ross, J. F., Finch, C. A., Peacock, W. C., and Sammons, M. E., The in vitro preservation and posttransfusion survival of stored blood. J. Clin. Invest., 1947, 26, 687.

3. Gibson, J. G., 2nd, Evans, R. D., Aub, J. C., Sack, T., and Peacock, W. C., The post-transfusion survival of preserved human erythrocytes stored as whole blood or in resuspension, after removal of plasma, by means of two isotopes of radio-active iron. $\mathrm{J}$. Clin. Invest., 1947, 26, 715.

4. Gibson, J. G., 2nd, and Evelyn, K. A., Clinical studies of the blood volume. IV. Adaptation of the method to the photoelectric micro colorimeter. J. Clin. Invest., 1938, 17, 153.

5. Shen, S. C., Ham, T. H., and Fleming, E. M., Studies on the destruction of red blood cells. III. Mechanism and complications of hemoglobinuria in patients with thermal burns: Spherocytosis and increased osmotic fragility of red blood cells. New England J. Med., 1943, 229, 701.

6. Shen, S. C., Castle, W. B., and Fleming, E. M., Experimental and clinical observations on increased mechanical fragility of erythrocytes. Science, 1944, $100,387$.

7. Gomori, G., A modification of the colorimetric phosphorus determination for use with the photoelectric colorimeter. J. Lab. \& Clin. Med., 1942, 27, 955.
8. Fiske, C. H., and Subbarow, Y., The colorimetric determination of phosphorus. J. Biol. Chem., 1925, 66, 375.

9. Rapoport, S., and Luebering, J., The formation of 2,3diphosphoglycerate in rabbit erythrocytes: the existence of a diphosphoglycerate mutase. J. Biol. Chem., 1950, 183, 507.

10. Mueller, C. B., and Hastings, A. B., Glycolysis and phosphate fractions of red blood cells. J. Biol. Chem., 1951, 189, 881.

11. Finch, C. A., Wolff, J. A., Rath, C. E., and Fluharty, R. G., Iron metabolism; Erythrocyte iron turnover. J. Lab. \& Clin. Med., 1949, 34, 1480.

12. Peacock, W. C., Evans, R. D., Irvine, J. W., Jr., Good, W. M., Kip, A. F., Weiss, S., and Gibson, J. G., 2nd, The use of two radioactive isotopes of iron in tracer studies of erythrocytes. J. Clin. Invest., 1946, 25, 605.

13. Burwell, E. L., Brickley, B. A., Finch, C. A., Erythrocyte life span in small animals. Comparison of two methods employing radioiron. Am. J. Physiol., 1953, 172, 718.

14. Stewart, W. B., Stewart, J. M., Izzo, M. J., and Young, L. E., Age as affecting the osmotic and mechanical fragility of dog erythrocytes tagged with radioactive iron. J. Exper. Med., 1950, 91, 147. 